\title{
Metals and Metalloids Removal from Mine Water Using Natural and Modified Heulandite
}

\author{
Natalya A. Abrosimova, Olga P. Saeva, Svetlana B. Bortnikova, Alexey V. Edelev, Tatyana V. \\ Korneeva, and Nikolay V. Yurkevich
}

\begin{abstract}
The paper represents the results of batch experiments on the extraction of $\mathrm{As}, \mathrm{Sb}, \mathrm{Zn}$, and $\mathrm{Cu}$ from real acidic and alkaline drainage solutions using natural and modified $\mathrm{MnO}_{2}$ heulandite $\left[\mathrm{AlSi}_{3} \mathrm{O}_{8}\right]_{2} \times \mathrm{Ca}\left(\mathrm{H}_{2} \mathrm{O}\right)_{5}$. It was found that the modified zeolite is effective for removal $\mathrm{As}$ and $\mathrm{Sb}$, but it is necessary to take into account the possibility of Mn releasing into the solution after interaction with acid drainage. For $\mathrm{Zn}$ removing from acid drainage solutions, the modified zeolite is not suitable. Both samples of heulandite effectively remove arsenic from the acidic solution as opposed to the alkaline solution. Perhaps this is due to the presence in the acid solution of a large amount of iron and aluminum, which during neutralization form hydroxides, contributing to additional sorption of the elements.
\end{abstract}

Index Terms - Batch experiment, drainage solution, modified zeolite, arsenic.

\section{INTRODUCTION}

Wastes from mining and processing plants stored in the tailing ponds have a negative impact on the system "water reservoir - soil - plant and animal world - people", so now studies are actively being carried out to neutralize ecological effect and recultivate of disturbed areas. Various methods are used to treat drainage water from metals and metalloids: ion exchange [1], electrochemical methods [2], membrane technologies [3], precipitation [4], [5].

Sorption extraction of metals from drainage solutions has become quite widespread due to high efficiency and the absence of secondary impurities. Correctly selected materials absorb metals from aqueous solutions practically to any residual concentrations [1], [6], [7]. In addition to environmental safety, natural sorbents (plant waste, coal, and zeolite) have economic benefits. In the world practice, the use of natural minerals as sorbents for water purification is encountered, but often such materials do not possess the necessary sorption properties and must be chemically and physically modified [8]. As a result of the modification, sorbents with a surface nature different from the original

Manuscript received December 13, 2018; revised May 12, 2019. This work was supported by the Russian Foundation for Basic Research under Grant 16-35-60053 and by the joint Russian-German program DAAD"Mikhail Lomonosov" and Ministry of Education and Science of Russia, project № 5.12753.2018/12.2.

The authors are with the Trofimuk Institute of Petroleum Geology and Geophysics, Siberian Branch of the Russian Academy of Sciences, Koptug Ave. 3, 630090 Novosibirsk, Russia and Tomsk Polytechnic University, Lenin Ave. 30, 634050 Tomsk, Russia (e-mail: AbrosimovaNA@ipgg.sbras.ru, SaevaOP@ipgg.sbras.ru, BortnikovaSB@ipgg.sbras.ru, KorneevaTV@ipgg.sbras.ru, nicolay_14283@mail.ru). mineral are obtained, combining the useful properties of the natural material and modified sorbents. Despite the frequent practical use of sorption methods in the purification of drainage solutions, there are a number of problems in this area. The most significant are: insufficient sorption capacity of the used materials, lack of reliable, cheap, eco-friendly methods for regenerating sorbents and methods for further utilization of heavy metals [8], [9]. Previously, studies were conducted using a modified and natural zeolite to purify acid and neutral solutions. In the literature, the following transformations of zeolites occur to increase the extraction efficiency of metals and metalloids: iron (hydr) oxide modification [10], surface modification by surfactants [11]. The purpose of this work was to compare the extraction efficiency of $\mathrm{As}, \mathrm{Sb}, \mathrm{Cu}$ and $\mathrm{Zn}$ from real drainage solutions with modified $\mathrm{MnO}_{2}$ heulandite and its natural analog. The effect of $\mathrm{pH}$ and the initial concentration of elements on the adsorption capacity of the zeolite was analyzed. The article presents the results of batch experiments on the treatment of subalkaline and acid drainage solutions from the Komsomolsk tailings impoundment and water from ponds on the surface of the Berikul mine tailings located in the village of Komsomolsk, Kemerovo region.

\section{METHODS}

Natural zeolite heulandite used in the experiments was extracted from a field in Western Siberia (OOO Sibir-Zeo). Prior to the experiments, a fraction of $0.5-0.25 \mathrm{~mm}$ of heulandite was isolated, washed with distilled water and dried at room temperature. The modification of the zeolite proceeded according to the following scheme [9]: $50 \mathrm{ml}$ of 2.5 $\mathrm{M} \mathrm{MnCl}_{2}$ was added with $0.5 \mathrm{ml}$ of $10 \mathrm{M} \mathrm{NaOH}$ and $50 \mathrm{~g}$ of zeolite were added to the resulting solution by a magnetic stirrer. The resulting mixture was heated for 5 hours at $150{ }^{\circ} \mathrm{C}$, and then for 3 hours at $500^{\circ} \mathrm{C}$. The modified zeolite was washed 3 times with distilled water and dried at room temperature. Photos of the natural and modified zeolites are shown in Fig. 1.

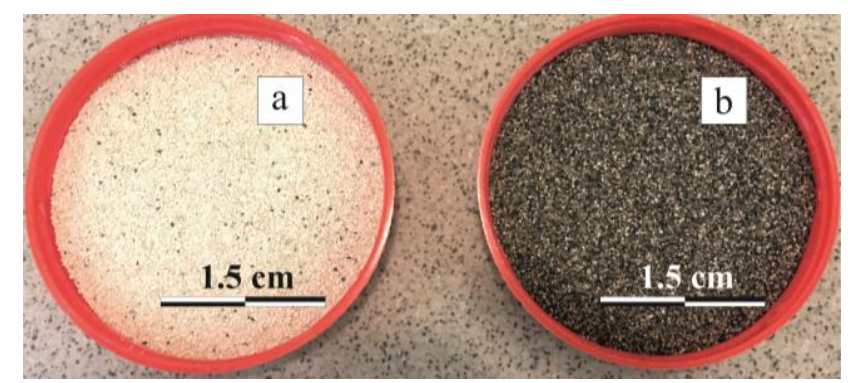

Fig. 1. Photographs of natural (a) and modified (b) zeolite used in the experiments. 
The elemental composition of the zeolite was studied by the ICP-MS method in the analytical centre "Plasma" (Tomsk) using the ELAN DRC-E mass spectrometer of PerkinElmer Instruments LLS (Certificate of Attestation, 2010) and the XRF method (analyst Yu. P. Kolmogorov). An electronic scanning microscope (SEM LEO $1430 \mathrm{VP}$ ) with an energy dispersive attachment (EDS (Oxford) spectrometer) was used to determine locations on the surface of sorbents that concentrate metals and metalloids and to study the morphology of the zeolite. Determination of the phase composition of the zeolite was carried out by X-ray diffraction analysis on a DRON 4 diffractometer with monochromatic $\mathrm{CuK} \alpha$ radiation (Research Center of IGM SB RAS, analyst N.A. Pal'chik, Ph.D). Samples of natural and modified zeolite before and after the experiments were investigated by IR spectroscopy to identify the functional groups involved in the sorption of the elements under consideration. Fourier transform infrared (FT-IR) spectra were recorded on a Specord 75 IR two-beam spectrophotometer in the wave number range from 400 to $4000 \mathrm{~cm}^{-1}$ with a tablet of spectrally pure $\mathrm{KBr}$ in the comparison channel. Samples were prepared by the method of pressing tablets with $\mathrm{KBr}$. Also IR spectra were recorded in the range from 370 to $4000 \mathrm{~cm}^{-1}$ on the Brotier VERTEX 70 FT-IR Fourier spectrometer in the absorption mode with a spectral resolution of $2 \mathrm{~cm}^{-1}$. To process the spectra, the software package OPUS (the Research Center of IGM SB RAS, analyst T.N. Moroz, Ph.D.) was used. To study the sorption and ion-exchange properties of zeolites, batch experiments were carried out: samples of zeolite (in grams) 5, 1.6, 1, 0.4, 0.1, 0.04, was transferred to a flask containing 20 $\mathrm{mL}$ of solution (Table 1), mixed and filtered through a 0.45 $\mu \mathrm{m}$ membrane filter. $10 \mathrm{ml}$ of samples were taken to determine the contents of $\mathrm{As}, \mathrm{Sb}, \mathrm{Cu}$, and $\mathrm{Zn}$ by the AAS method using the SOLAAR spectrometer, M6 series (IGM SB RAS Research Center, analyst N.V. Androsova). The other part of the sample was used to measure $\mathrm{pH}, \mathrm{Eh}, \mathrm{EC}$.

TABLE I: PHYSICO-CHEMICAL PARAMETERS AND CONCENTRATIONS (MG/L) OF SOME ELEMENTS IN THE DRAINAGE SOLUTIONS.

\begin{tabular}{cccc}
\hline \hline & KOM & BER & MPC \\
\hline $\mathrm{pH}$ & 8.1 & 2.5 & \\
$\mathrm{Eh}[\mathrm{mV}]$ & 400 & 734 & \\
$\mathrm{As}$ & 0.22 & 0.60 & 0.01 \\
$\mathrm{Sb}$ & 0.75 & 0.0058 & 0.005 \\
$\mathrm{Zn}$ & 0.53 & 9.0 & 1 \\
$\mathrm{Cu}$ & 0.0093 & 1.9 & 1 \\
\hline \hline
\end{tabular}

Note: $\overline{\overline{\mathrm{KOM}} \text { - water from Komsomolsk tailings impoundment; BER }}$ - water from ponds on the surface of the Berikul mine tailings; MPC according to the normative document [12].

\section{RESULTS AND DISCUSSION}

By composition, the used zeolite belongs to the subfamily of high-silica zeolites. FT-IR spectra of natural and modified zeolites are shown in Fig. 2 and 3.

The observed absorption bands in the FT-IR spectrum of the zeolite refer to the internal vibrations of $\mathrm{Si}-\mathrm{O}-\mathrm{Si}, \mathrm{Si}-\mathrm{O}-\mathrm{Al}$ bonds in $\mathrm{SiO}_{4}$ and $\mathrm{AlO}_{4}$ tetrahedra and characterize zeoliteheulandite [13], [14]. An intense band of an antisymmetric stretching vibration of Si-O-Si of about $1058 \mathrm{~cm}^{-1}$ with arms
$1140 \mathrm{~cm}^{-1}, 1200 \mathrm{~cm}^{-1}$ was registered. The exact position of this band depends on the ratio $\mathrm{nSi} / \mathrm{nAl}$ in the crystalline framework [15]. The band of the symmetric valence vibration of $\sim 794 \mathrm{~cm}^{-1} \mathrm{Si}-\mathrm{O}-(\mathrm{Si}, \mathrm{Al}=\mathrm{T})$, double 4 and 6-ring $\sim 722$, $605 \mathrm{~cm}^{-1}$ and the deformation vibration of the T-O bond $\sim 470$ $\mathrm{cm}^{-1}$ was registered. The $3421 \mathrm{~cm}^{-1}$ band in the valence vibration region of $\mathrm{OH}$ bonds refers to loosely bound water molecules in the zeolite framework. The FT-IR spectrum of the modified zeolite is practically unchanged, the shift of the stretching vibration band of the Si-O bond from 1058 to 1066 $\mathrm{cm}^{-1}$ is observed in the spectrum of the modified sample (Fig. 3a) and the shift to $3446 \mathrm{~cm}^{-1}$ and broadening of the stretching vibration band $\left(\mathrm{H}_{2} \mathrm{O}\right) \mathrm{Me}\left(\mathrm{H}_{2} \mathrm{O}\right)$ connections (Fig. 3b). The FT-IR spectrum of the zeolite after the experiments remains practically unchanged, which indicates the preservation of short-range order in the structure of the zeolite, with the exception of the spectrum in the valence vibration region of $\mathrm{OH}$ bonds, which is due to redistribution of the $\left(\mathrm{H}_{2} \mathrm{O}\right) \mathrm{Me}\left(\mathrm{H}_{2} \mathrm{O}\right)$ bonds in the zeolite framework.

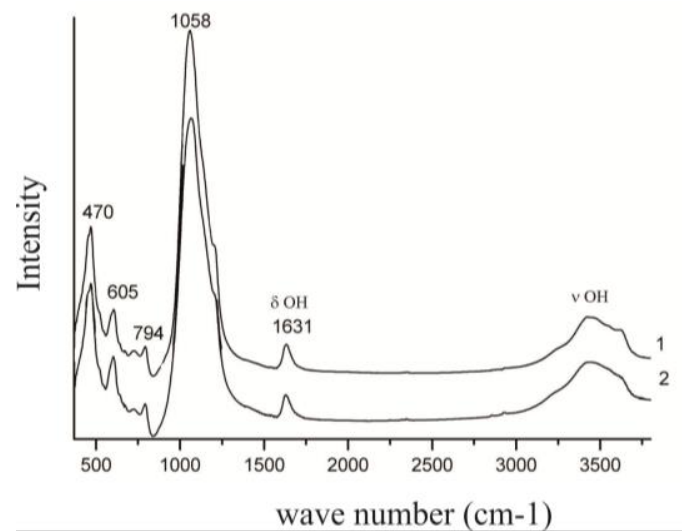

Fig. 2. FT-IR spectra of zeolites in the range from 400 to $3800 \mathrm{~cm}^{-1}$. Zeolite (1), zeolite after an experiment with "BER" solution (2).

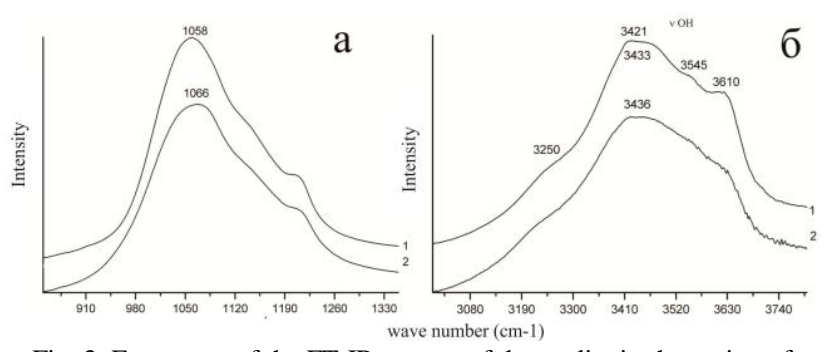

Fig. 3. Fragments of the FT-IR spectra of the zeolite in the region of stretching vibrations: (a) OH groups: zeolite (1), modified zeolite (2); (b) $\mathrm{Si}$, Al-O groups: zeolite (1), modified zeolite (2).

When the zeolite interacts with an alkaline solution with an initial $\mathrm{pH}$ of 8.1 and an As the content of $0.22 \mathrm{mg} / \mathrm{l}, \mathrm{Sb} 0.75$, the $\mathrm{pH}$ value decreases to slightly acidic values. For modified zeolite, noticeable changes in $\mathrm{pH}$ values begin with a water $/$ rock $=50$, for a natural zeolite at a $\mathrm{W}: \mathrm{R}$ ratio $=20$. To remove $\mathrm{As}$ and $\mathrm{Sb}$ from water from Komsomolsk tailings impoundment, the modified zeolite is more efficient (Fig. 4). The natural zeolite also showed a good result and sorbed 39\% of As and $76 \%$ of $\mathrm{Sb}$ from the solution at a ratio of $\mathrm{W}: \mathrm{R}=4$. By modified zeolite $93 \%$ - As and 53\% - Sb were sorbed and $27 \% \mathrm{As}$ and $29 \% \mathrm{Sb}$ were sorbed by its natural analog, respectively, at a ratio of $\mathrm{W}: \mathrm{R}=20$.

A batch experiment on the interaction of an acid Berikul solution with a natural and modified zeolite was carried out 
under the same conditions as the experiment with water from Komsomolsk tailings impoundment. Modified and natural heulandite increased the $\mathrm{pH}$ of the acid drainage solution (BER) from 2.5 to 4.5 at a ratio $(\mathrm{W}: \mathrm{R})=4: 1$. The modified zeolite proved to be ineffective for removal $\mathrm{Zn}$ from water from ponds on the surface of the Berikul mine tailings only $8 \%$ of $\mathrm{Zn}$ was sorbed with a minimum $\mathrm{W}: \mathrm{R}$ ratio.

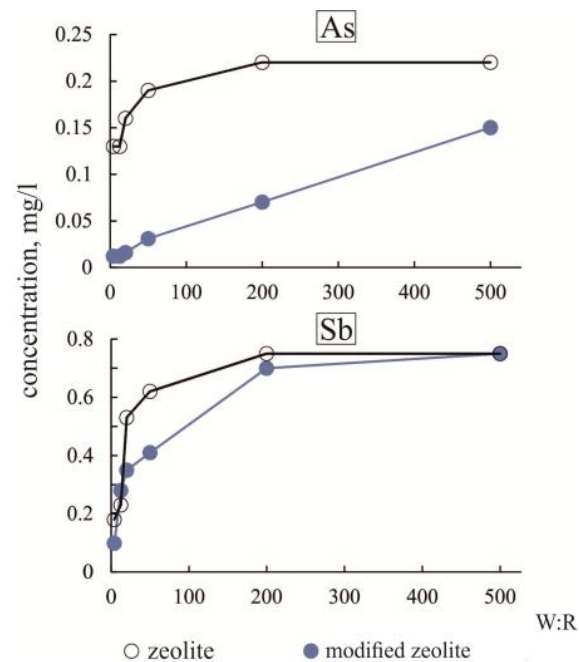

Fig. 4. Change in element concentrations during experiment on interaction of water from Komsomolsk tailings impoundment with a modified/natural zeolite.

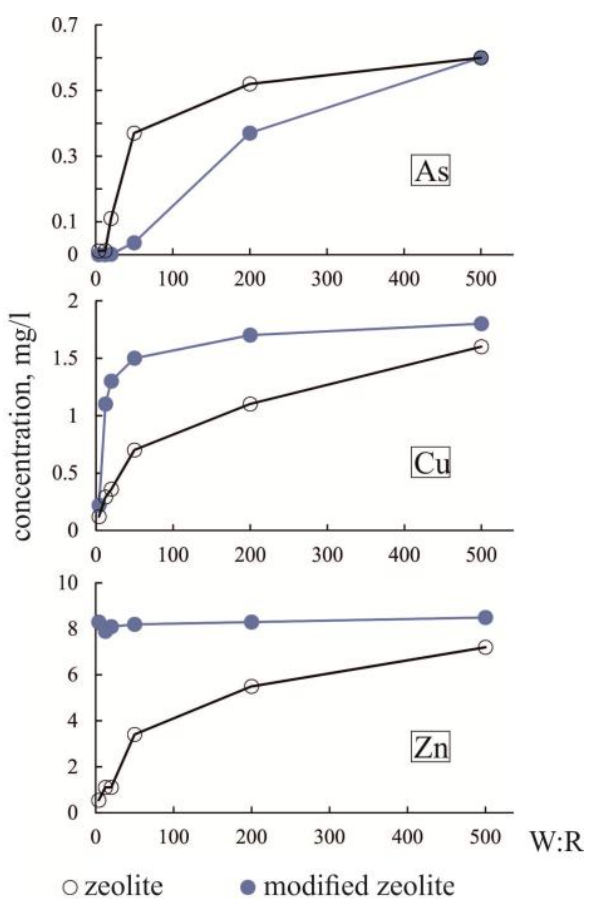

Fig. 5. Change in element concentrations during the experiments on interaction of water from ponds on the surface of the Berikul mine tailings with a modified/natural zeolite.

The content of $\mathrm{Cu}$ in the solution was significantly decreased in comparison with the initial solution only at the ratio water: rock $=12.5$. However, the modified zeolite sorbed As to a level below the detection limit $(0.001 \mathrm{mg} / \mathrm{l})$ at a ratio of $\mathrm{W}: \mathrm{R}=20$, while the natural zeolite sorbed $82 \%$ at a given $\mathrm{W}: \mathrm{R}$ ratio (Fig. 5).

In the course of the experiment, as the ratio of $\mathrm{W}: \mathrm{R}$ decreases, the element species in solutions change. The $\mathrm{pH}$-Eh diagrams show changes in the species for $\mathrm{Al}$ and $\mathrm{Fe}$ (Fig. 6). It is evident that in the course of the experiment it is possible to form iron and aluminum hydroxides, which are capable to sorb metals and metalloids from solutions.
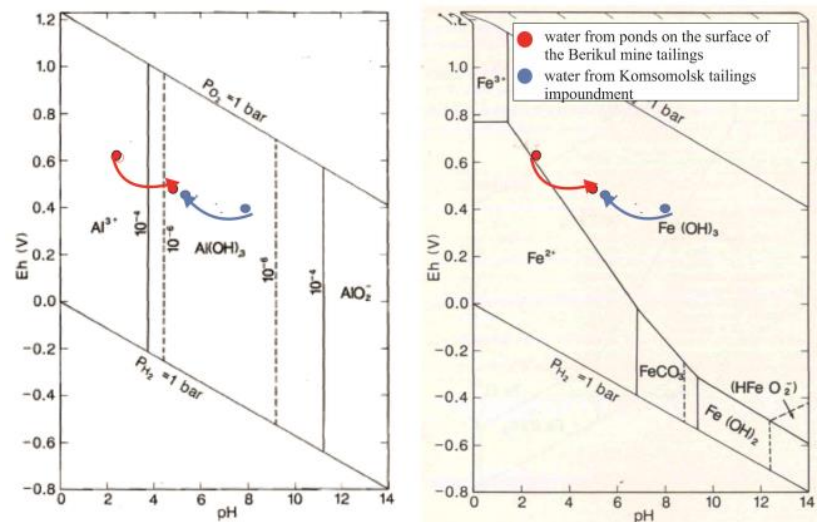

Fig. 6. pH-Eh diagrams modified from [16]. The arrows indicate the change in the physico-chemical parameters of solutions during the experiments

The following processes are important during the removal of elements from the solution: ion exchange, adsorption, and sorption on newly formed iron and aluminum hydroxides.

\section{CONCLUSION}

Modified $\mathrm{MnO}_{2}$ zeolite can be used to remove $\mathrm{As}, \mathrm{Sb}, \mathrm{Cu}$ from drainage water (for both alkaline and acid solutions) but consider the possibility of releasing Mn (hazard class 3 ) into the solution. Optimum water:rock ratios for the modified and natural zeolite is 20-50. Since such proportions achieve significant percentages of deposition of the elements. Also, the maximum contents of metals and metalloids for natural zeolite were $12 \mu \mathrm{g}$-As, $6.5 \mu \mathrm{g} / \mathrm{g}$-Sb, $60 \mu \mathrm{g}-\mathrm{Cu}, 280 \mu \mathrm{g}-\mathrm{Zn}$ per $\mathrm{g}$ of material and for the modified: As $-28 \mu \mathrm{g} / \mathrm{g}, \mathrm{Sb}-17$ $\mu \mathrm{g} / \mathrm{g}, \mathrm{Cu}-20 \mu \mathrm{g} / \mathrm{g}, \mathrm{Zn}-40 \mu \mathrm{g} / \mathrm{g}$. Thus, to treat drainage water from metals, it is worth choosing a natural mineral, and to extract metalloids from the solution, a modified one. In an acid solution, arsenic sorption is better for both natural and for modified zeolite, in contrast to the alkaline solution. Perhaps this is due to the neutralization reaction and the formation of iron hydroxide capable of sorbing the elements from the solution.

\section{CONFLICT OF INTEREST}

The authors declare no conflict of interest.

\section{AUTHOR CONTRIBUTIONS}

Conceptualization, N.A.; methodology, N. Yu., S. B., N. A., A.D.; investigation, N. A., O. S., A. E., T. K..; resources, N. A.; writing-review and editing, S. B., N. Yu., N. A.; visualization, O. S., N. A., N. Yu.; supervision, N. A.; project administration, N. A.; funding acquisition, N. A. All authors had approved the final version.

\section{REFERENCES}

[1] S. E. Bailey, T. J. Olin, R. M. Bricka, and D. D. Adrian, "A review of potentially low-cost sorbents for heavy metals," Water research, vol. 33, no. 11, pp. 2469-2479, August 1999.

[2] O. P. Saeva, N. V. Yurkevich, and V. G. Kabannik, "The electrochemical remediation of acid drainage," presented at the 13th International Conference on Water-Rock Interaction, Guanajuato, Mexico, August 16-20, 2010. 
[3] H. Al-Zoubi, A. Rieger, P. Steinberger, W. Pelz, R. Haseneder, and G. Härtel, "Optimization study for treatment of acid mine drainage using membrane technology," Separation Science and Technology, vol. 45, no. 14, pp. 2004-2016, September 2010.

[4] N. V. Yurkevich, O. P. Saeva, and N. A. Pal'chik, "Arsenic mobility in two mine tailings drainage systems and its removal from solution by natural geochemical barriers," Applied Geochemistry, vol. 27, no. 11, pp. 2260-2270, November 2012.

[5] N. Abrosimova, O. Saeva, N. Yurkevich, and S. Bortnikova, "Treatment of neutral mine waters from metals and metalloids," presented at the 17th International Multidisciplinary Scientific GeoConference SGEM, Albena, Bulgaria, 29 June-5 July, 2017.

[6] M. Makarova, N. Abrosimova, E. Rybkina, R. Fiaizullina, and I Nikolaeva, "Experimental investigation of sorption of microelements from mine drainage on zeolite and clay," presented at the 17th International Multidisciplinary Scientific GeoConference SGEM, Albena, Bulgaria, 29 June-5 July, 2017.

[7] R. Fiaizullina, M. Makarova, and N. Abrosimova, "The possibility of wastewater treatment of heavy metals by natural sorbents," presented at the 17th International Multidisciplinary Scientific GeoConference SGEM, Albena, Bulgaria, 29 June-5 July, 2017.

[8] E. S. Klimova and M. V. Byzaeva, Natural Sorbents and Complexones in Wastewater Treatment, Ulyanovsk, Russia: UISTU, 2011, pp. 80-83.

[9] L. M. Camacho, R. P. Ramona, and S. Deng, "Arsenic removal from groundwater by $\mathrm{MnO}_{2}$-modified natural clinoptilolite zeolite," Journal of Hazardous Materials, vol. 189, no. 1, pp. 286-293, May 2011.

[10] P. M. Nekhunguni, N. T. Tavengwa, and H. Tutu, "Investigation of as (V) removal from acid mine drainage by iron (hydr) oxide modified zeolite," Journal of environmental management, vol. 197, pp. 550-558, July 2017

[11] M. E. Jiménez-Castañeda and D. I. Medina, "Use of surfactant-modified eolites and clays for the removal of heavy metals from water," Water, vol. 9, no. 4, p. 235, March 2017.

[12] Maximum Permissible Concentration (MPC) of Chemical Substances in the Water of Drinking and Cultural-Domestic Water Objects, RMH, Russian Ministry of Health, Moscow, Russia, HN 2.1.5.1315-03.

[13] H. Moenke, Mineralspektren, Berlin: Akademie-Verlag, 1962, p. 234

[14] J. A. Gadsden, Infrared Spectra of Minerals and Related Inorganic Compounds, Butterworths, 1975, p. 277.

[15] M. Ostrooumov, P. Cappelletti, and R. Gennaro, "Mineralogical study of zeolite from New Mexican deposits (Cuitzeo area, Michoacan, Mexico)," Applied Clay Science, vol. 55, pp. 27-35, January 2012.

[16] D. G. Brookins, Eh-pH Diagrams for Geochemistry, Springer-Verlag Berlin Heidelberg, 1988, p. 45.

Copyright $\odot 2019$ by the authors. This is an open access article distributed under the Creative Commons Attribution License which permits unrestricted use, distribution, and reproduction in any medium, provided the original work is properly cited (CC BY 4.0).

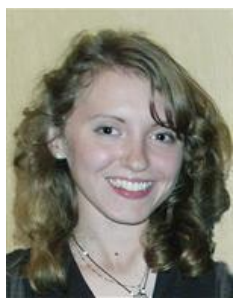

Natalya A. Abrosimova was born in Novosibirsk, Russia. She received the B.Sc. and the M.Sc. degree in Novosibirsk State University and Ph.D. degree in Trofimuk Institute of Petroleum Geology and Geophysics, Siberian Branch of the Russian Academy of Sciences in 2007, 2009, and 2013, respectively. From 2009 to 2014, she had been a research assistant at Lab. Geoelectrochemistry in Trofimuk Institute of Petroleum Geology and
Geophysics, Siberian Branch of the Russian Academy of Sciences. She has been scientist since 2014 at the same department. Her research interests include geochemistry of water/rock interaction in natural and technogenic systems.

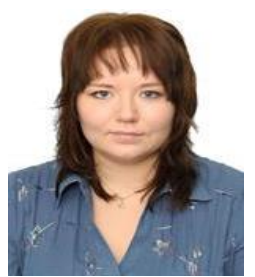

Olga P. Saeva received the B.Sc. and the M.Sc. degree in Novosibirsk State University and Ph.D degree in Trofimuk Institute of Petroleum Geology and Geophysics, Siberian Branch of the Russian Academy of Sciences. From 2009 to 2014, she had been a research assistant in Trofimuk Institute of Petroleum Geology and Geophysics, Siberian Branch of the Russian Academy of Sciences. Her research interests include development of methods of remediation of mine drainage.

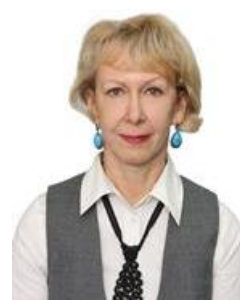

Svetlana B. Bortnikova is a doctor and professor and a leader of a laboratory of. Geoelectrochemistry in Trofimuk Institute of Petroleum Geology and Geophysics, Siberian Branch of the Russian Academy of Sciences. Her research interests include geochemistry of elements, anthropogenic geochemical anomalies in the areas of mining waste storage, geochemical barriers, reclamation of disturbed territories, experimental and thermodynamic modeling of migration and deposition of elements in natural-technogenic systems, geophysical methods of investigation of technogenic systems.

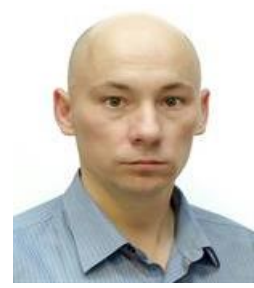

Alexey V. Edelev received the B.Sc. and the M.Sc degree in Novosibirsk State University and Ph.D degree in Trofimuk Institute of Petroleum Geology and Geophysics, Siberian Branch of the Russian Academy of Sciences. His research interests include geochemistry of water/rock interaction in natural and technogenic systems.

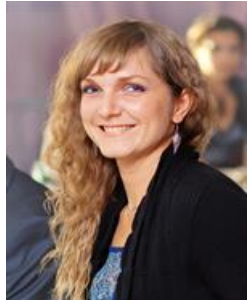

Tatyana V. Korneeva received the B.Sc. and the M.Sc. degree in Novosibirsk State University and Ph.D. degree in Trofimuk Institute of Petroleum Geology and Geophysics, Siberian Branch of the Russian Academy of Sciences Her research interests include geochemistry of water/rock interaction, experimental and thermodynamic modeling of migration and deposition of elements in natural-technogenic systems.



Nikolay V. Yurkevich received the B.Sc., the M.Sc., and Ph.D. degree in Novosibirsk State Technical University. His research interests include: problems of development and operation of oil and gas fields, development of methods for improving the recovery of the reservoir, ecology in the oil and gas complex, methods design for the development of hard-to-recover reserves, including Bazhenov formation. 